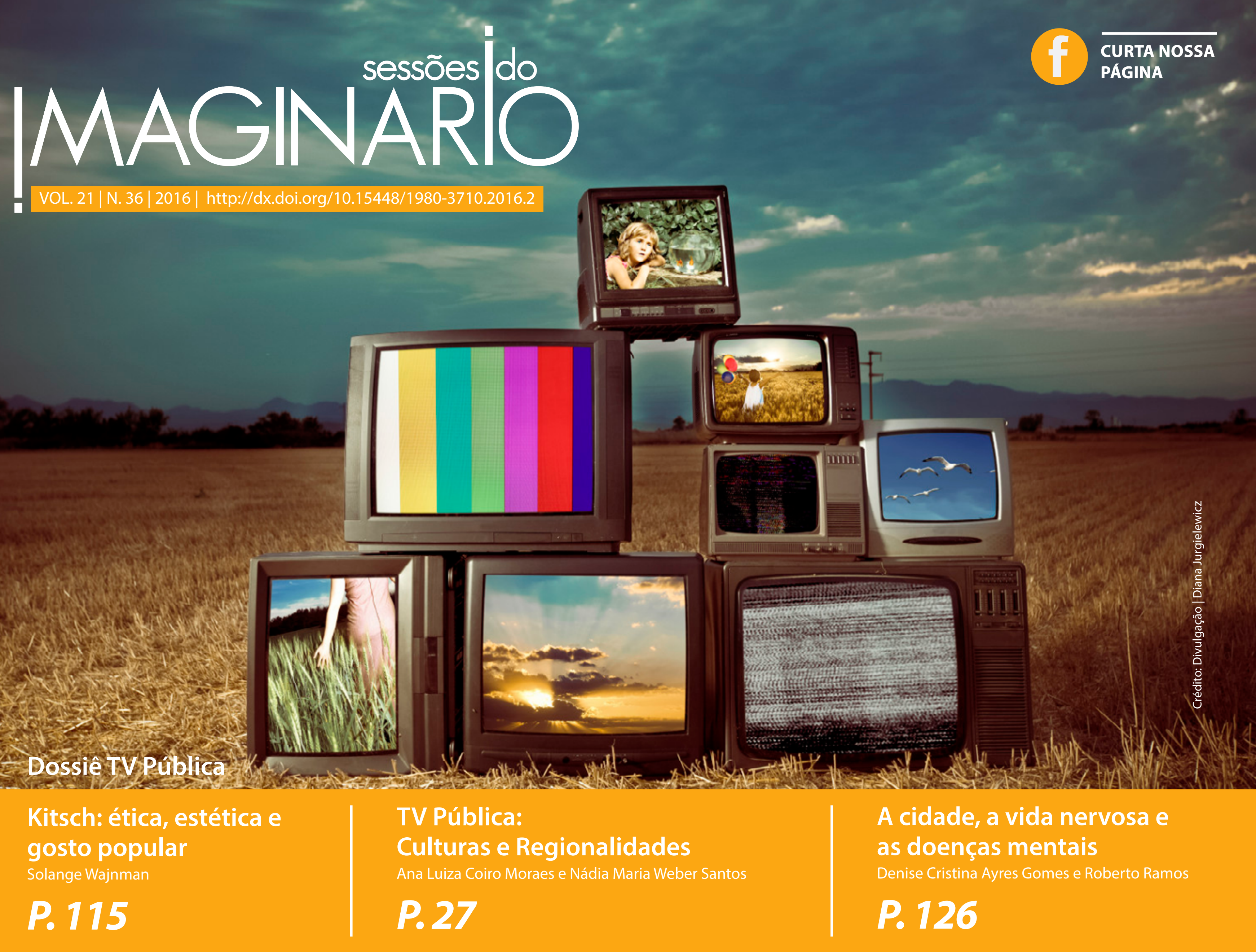




\section{Ética e estética do kitsch: subsídios para o estudo do gosto popular na experiência contemporânea}

\author{
Ethics and aesthetic of kitsch: \\ grants for the study of popular style \\ in contemporary experience
}

\section{Solange Wajnman' ${ }^{\top}$}

\section{Resumo}

Para além do mau gosto, da ornamentação excessiva, da sentimentalidade desmesurada de algumas das camadas populares e dos falsos originais daqueles que concorrem rumo ao pódio artístico-social, o kitsch pode ser compreendido como uma "forma" dinâmica na experiência contemporânea. Argumentamos aqui a favor da construção de um instrumental teórico-metodológico comum a algumas das lógicas da estética popular e práticas artísticas e/ou tecnológicas atuais. Tal instrumental é proposto a partir da articulação de eixos conceituais derivados das lógicas do empilhamento, da heterogeneidade, da sedimentação, da transposição e do deslocamento e das noções de alegoria e bricolagem.

\section{Palavras-chave}

Kitsch; estética; gosto popular; forma.

\section{Abstract}

Far beyond bad taste, excessive ornamentation, disproportionate sentimentality in some popular layers, and also the fake originals of those who are eager to climb the social-artistic podium, kitsch can be understood as a dynamic 'form' in the contemporary experience. We hereby argue for the construction of a theoretical-methodological instrumental which is common to the logic of some of the popular aesthetics as well as some current artistic and/or technological practices. Such instrumental is thus proposed as originating not only from the articulation of conceptual axe deriving from the logic of stacking, heterogeneity, sedimentation, transposition and displacement, but also the notions of allegory and bricolage.

\section{Keywords}

Kitsch; aesthetics; popular taste; form. 


\section{Introdução}

Sem nos determos aqui na etimologia da palavra alemã, podemos dizer que o substantivo kitsch corresponde a um tipo de fenômeno social e estético cuja genealogia remonta à ascensão dos burgueses e a seu enriquecimento proporcionado pela revolução industrial em meados do século XIX. Se não trazia um puro sangue aristocrata, o burguês procurava, de certa forma, se igualar aos nobres pelo uso indiscriminado e excessivo de decoração, arquitetura e vestuário. Como entender a continuidade desse fenômeno para além desse contexto e seu alcance por outras classes sociais? Em parte, podemos dizer com Cardoso (2008) que a ânsia pelo estilo e afirmação pessoal persiste até hoje no conjunto social, sobretudo entre as camadas menos abastadas. E ainda, podemos entender a continuidade desse fenômeno facilitada pelo fim das hierarquias rígidas entre as classes sociais e pelo desenvolvimento da indústria e dos bens de consumo. Mas esta explicação não nos é suficiente. Há que se acrescentar ao fenômeno, além de sua explicação histórica, uma compreensão da dinâmica interna desse gosto. Para tal tarefa trataremos de construir o recurso metodológico da "forma" que designa o instrumento capaz de captar o movimento dos fenômenos antes que eles se cristalizem e se reifiquem, conforme os princípios de Georges Simmel e Michel Maffesoli. ${ }^{2}$

"Forma" para estes dois autores significa o instrumento epistemológico capaz de apreender o movimento de "vai e vem" que se passa entre o conceito e a vida. "A 'forma' é formante e não apenas formal" 3 , escreve Maffesoli (1985, p. 21). Trata-se de um instrumento que permite apreender as estruturas e seus desenvolvimentos ao mesmo tempo em que torna possível a existência das realidades singulares. Nesse contexto, nossa atitude epistemológica diante do kitsch é "formista", pois este é considerado aqui como uma figura aglomerante capaz de integrar a vida social à estética. Nosso olhar percorre um incessante "vai e vem" entre algumas das representações populares e a discussão estética propriamente dita.

A "forma" enquanto operação metodológica é o resultado de uma rede de conexões que se estabelece aparentemente a partir de elementos diversos. Ela permite inicialmente as composições, as reuniões de elementos díspares que se poderá em seguida analisar e comparar (Cf. Maffesoli, 1985, p. 22). Assim, não se trata de submeter o fenômeno (como o kitsch, por exemplo) a um postulado dado a priori, nem de fazer dele uma lei determinista, mas de mostrá-lo, ao contrário, como o resultado de uma rede de conexões. Lembremos aqui o pensamento de Weber a propósito da pluricausalidade muito oportuno para evidenciar como se efetua a dinâmica da "forma".

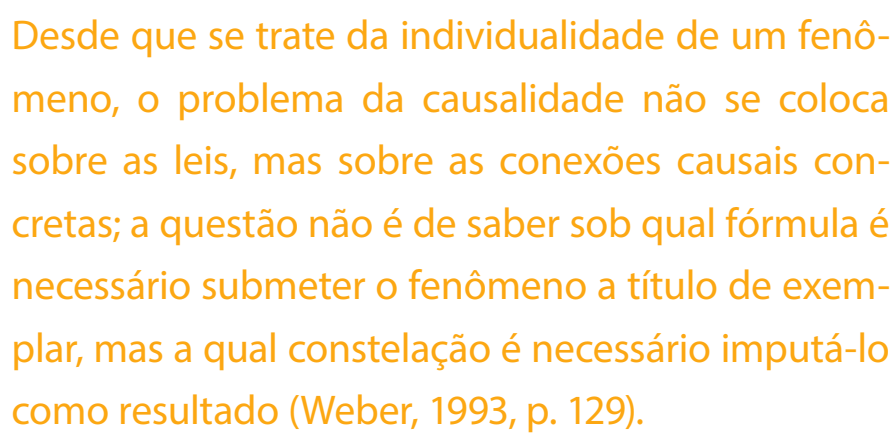

Neste sentido, tratar-se-á de apreender a individualidade do fenômeno do kitsch a partir de várias conexões. Sem naturalmente esgotar todas as conexões, nós esperamos capturar uma série de elementos importantes que tornam possível a configuração do fenômeno. Indicamos aqui que o kitsch se encontra tanto em algumas modulações da estética popular, como se manifestando, inclusive, nas práticas artísticas e/ou tecnológicas atuais.

Ainda dentro desta explanação acerca do instrumental da forma é preciso evidenciar que os múltiplos domínios do kitsch são aglomerados a partir de vetores que os estruturam e os dinamizam. Estes vetores são delineados por nós a partir dos eixos derivados das lógicas do empilhamento, da heterogeneidade, da sedimentação, da transposição e do deslocamento, como mostraremos na revisão conceitual do kitsch no próximo item. E é ainda importante atentar para o uso que faremos das noções de alegoria e bricolagem, conceitos advindos da antropologia de Lévi-Strauss e da filosofia de Walter Benjamin, nossos substratos teóricos maiores e que possibilitam a operacionalização da "forma" kitsch. Trataremos destas duas noções, bricolagem e alegoria, no item dedicado às representações populares.

\section{Em busca de uma "forma" kitsch}

Os estudos consagrados sobre o kitsch, como aqueles de G. Dorfles (1978), H. Broch (1978) e Moles (1971), mostram que sua abrangência não se limita apenas à estética do mau gosto. De fato, eles argumentam que às miniaturas da torre Eiffel ou da estátua da Liberdade e aos gnomos de jardim subjaz uma ética interna incontornável.

Para G. Dorfles (1978), o homem kitsch é aquele que reage de maneira irreversivelmente falsa diante das obras de arte. Ele explica: 
símbolo de status e não como componente grave de existência, exercício penoso de atividade engajada e crítica $^{4}$ (Dorfles, 1978, p. 27).

Efetivamente, para G. Dorfles o kitsch não é somente uma estética, ele traria também uma atitude ética. Da mesma maneira, no pensamento de $\mathrm{H}$. Broch se encontra uma reflexão sobre essa atitude. Para ocultar a angústia da morte e para se tranquilizar, o homem kitsch altera o sistema de valores da arte tornando-o fechado e absoluto. Ele transforma o "bom trabalho" em "belo trabalho".

Em que tipo de obra de arte, ou melhor, de artifício o kitsch tende a transformar a vida humana? A resposta é simples: em obra de arte neurótica, em obra que impõe à realidade uma convenção completamente irreal ou aprisionando-a em um esquema falso. ${ }^{5}$ (Broch, 1978, p. 71-72).

Outra concepção semelhante é encontrada no pensamento de A. Moles (1971). Segundo este autor, o kitsch faz parte de uma ética da felicidade. Os valores que compõem esta ética são:

- segurança em relação aos perigos do mundo exterior, mundo este visto como um valor ideal;

afirmação de si mesmo, ausência de questionamento sobre um modo de vida ou de um sistema econômico baseado sobre a acumulação econômica e sua conservação, quer se trate de capital, de mercadorias, de grandes lojas ou objetos;

- sistema possessivo como valor essencial ou o ser é o que parece, e parece por suas possessões; tamanho do apartamento, altura do teto ou baixelas de prata;
- Gemütlichkeit, relacionada à alma e ao coração, o conforto do coração, intimidade agradável e afetuosa, virtude de se sentir à vontade (...);

ritual de modo de vida6 (Moles, 1971, p. 84).

Embora possamos reter algumas das diretrizes destes autores para compor a "forma" do kitsch, apontamos, entretanto, para a desconfiança deles em relação à atitude do homem kitsch. Publicadas nos anos $1970 \mathrm{e}$ 1980, tais concepções se aproximavam de uma visão de vida eleita pelos intelectuais como a correta, a verdadeira. Evidenciava-se aí a lógica do "dever ser". No entanto, em uma sociedade como a nossa, onde a comunicação de massa, publicidade e o desenho industrial no seu conjunto estetizam todos os objetos, esta separação $a$ priori entre o que é verdadeiro e o que é falso nos parece hoje inadequada e mesmo anacrônica.

Ora, não se trata apenas de apontar uma atitude kitsch isolada aqui e lá. Podemos reter, talvez, a ideia da presença do espírito romântico ${ }^{7}$ na atitude kitsch, mas não podemos construir uma "forma" kitsch baseada em paradigmas de ordem moral.

Na verdade, não há uma definição simples. Trata-se de um fenômeno que contempla uma variedade de áreas e excede todas as fórmulas deterministas pelas quais se tentou apreendê-lo. Ele não pode ser reduzido a estas, uma vez que está em movimento e que atravessa variados domínios (éticos, semióticos, estéticos e culturais), assim como épocas diferentes. Esse caráter mutável do kitsch, bem como sua propagação atual na cultura midiática, na moda, na decoração de lojas e até mesmo na arte, nos mostra a necessidade de um quadro teórico-metodológico que seja capaz de se adaptar à sua instabilidade. Talvez devêssemos nos referir ao fenômeno como o "neo-kitsch".
De qualquer forma, esta discussão surge a partir da necessidade de articular o conceito com algo que advém do kitsch, mas que ainda não é nomeado. Evidentemente, alguns autores vislumbraram neste kitsch vestígios de uma estética contemporânea. Umberto Eco, por exemplo, observava já ao final dos anos 1960 que não é apenas o sistema kitsch que se nutre da cultura erudita, simplificando-a e banalizando-a. Também acontece o contrário. As tendências de vanguarda da arte contemporânea se nutrem, por sua vez, do kitsch. De acordo com Eco, a arte pop seria um exemplo daquilo que transforma os símbolos gráficos mais vulgares (histórias em quadrinhos, marcas de bebida, etc.) em objeto irônico, cuja imagem é ampliada e depois exposta. Essa incorporação do kitsch na cultura de vanguarda é, para ele, totalmente crítica. Deslocando esses produtos do contexto kitsch para o contexto da arte, o artista pop, segundo Eco, estaria se vingando do kitsch. Tratar-se-ia, então, de um ato de vingança em que a cultura "culta" mostraria ao kitsch como se podem inserir objetos estranhos num novo contexto sem pecar contra o bom gosto (Eco, 1979). Outros autores, como G. Dorfles, veem ainda na incorporação do kitsch pela vanguarda artística uma estratégia consciente. Essa estratégia promoveria o que é banal, excessivo, de mau gosto, no Camp da estética e da arte. Para ele, o termo Camp define: "utilização consciente e intencional do kitsch por certos artistas contemporâneos (Duchamps, Picasso, De Chirico, etc.), bem como a utilização pelo público de elite, culturalmente sofisticado, de elementos pertencentes nitidamente ao kitsch (móveis, objetos de decoração, quadros, estátuas, etc.), mas recuperados por uma certa atitude por parte do consumidor, (...) e que se constitui, num certo sentido, no contrapé do kitsch"8 (Dorfles, 1978, p. 296). Trazendo a palavra de S. Sontag, Dorfles completa essa definição 
afirmando que "a essência do Camp é seu amor pelo que não é natural, pelo artifício, pelo excesso" ${ }^{\prime \prime}$. A partir desse comentário, o autor pôde concluir: "O Camp é então uma atitude particular, sofisticada e um tiquinho esnobe, pelo qual se opera uma espécie de resgate, de recuperação de um material destinado, frequentemente, senão sempre, ao lixo. No outro caso, o Camp permite reavaliar o que, em si, não teria muito valor"10 (Dorfles, 1978, p. 296).

Enfim, não temos condições aqui de desenvolver todas estas questões acerca do alcance do kitsch no mundo contemporâneo. Mas podemos dizer, pelo teor da discussão, que são questões apenas sugeridas e que não se constituem ainda como proposição teórica satisfatória para a compreensão do fenômeno. Por outro lado, embora conscientes dos limites modestos deste trabalho e de seu caráter de work in progress, nossa proposta teórico-metodológica é a construção de uma "forma" do kitsch. Esta poderia ser, segundo nosso argumento, organizada a partir de três eixos e um modo operacional que os reúne. Os três eixos são:

\section{Estrutura e lógica do kitsch}

2 Representações estéticas populares

3 Arte e representações estéticas tecnológicas

Por estes três eixos atravessa um procedimento que deriva do trabalho do sistema de bricolagem e da alegoria. Tal procedimento atravessa cada um destes itens, como argumentaremos a seguir, e movimenta uma dinâmica que conduz, de um lado, à fragmentação, e de outro, à totalidade. Tratemos, pois, desta dinâmica nos três eixos.

\section{Estrutura e lógica do kitsch}

Para caracterizar o sistema kitsch devemos compreender a sua estrutura e lógica interna. Vimos acima a de- finição de valores que se depreendem da ética kitsch, segundo Moles (1971). Nós Ihe daremos novamente a palavra no que diz respeito às características estruturais do kitsch. Segundo ele os critérios que podem definir o kitsch são:

1) Critério de empilhamento sem limite: um con junto kitsch é constituído de objetos diversificados e empilhados em um espaço com volume restrito [...]

2) Critério de heterogeneidade: os objetos reunidos não têm relação direta uns com os outros [...]

3) Critério de antifuncionalidade: Este critério corres ponde à distinção entre a série funcional, aquela por exemplo dos instrumentos cirúrgicos colocados lado a lado sobre a bandeja auxiliar da mesa de operações, aquela do conjunto de utensílios de um restaurante ou a série de instrumentos do instituto de beleza e o agrupamento espontâneo de caráter sedimentar da coleção de panelas de todos os tipos e formas, ou aquela do ferro de passar, da cozinha ou do salão burquês. A funcionalidade impõe séries precisas de objetos que respondem a critérios utilitários.

4) Critério de sedimentação: O kitsch raramente o produto de um projeto deliberado, como poderia ser o caso de um decorador. Ele é, ao contrário um desenvolvimento lento, um acúmulo triunfante de viagens e testemunhos de exotismo, troféus de ascensão social, ou socioeconômica, promessas de uma sedução pelo mercado e um pensamento artístico fragmentado que consegue enxergar claramente o objeto, mas não o conjunto do projeto" (Moles, 1971, pp. 51-53).
As outras características lógicas do kitsch são as transposições e os deslocamentos. É isto que nos mostram G. Dorfles e V. Gregoretti.

Para G. Dorfles (1978), se a transposição de uma palavra (de um signo ou de uma imagem) fora de seu contexto lhe confere um novo vigor, quando se trata de arte, isto se transforma, no caso do sistema kitsch, em qualquer coisa de falso e desprovido de autenticidade. O autor dá alguns exemplos:

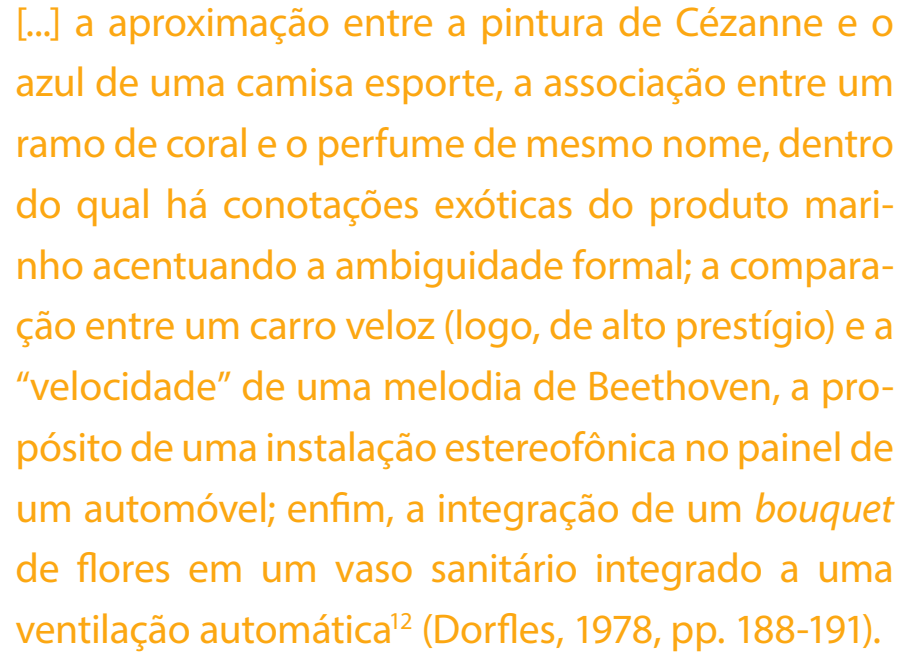

Para V. Gregoretti (1978), da mesma maneira, uma das regras de estrutura do objeto kitsch é o deslocamento de significado. Mas, ao contrário da obra criativa autêntica, onde este desvio pode fundamentar uma nova compreensão do mundo, no kitsch "trata-se de uma caricatura 'ou ainda de' fazer deslizar a operação do plano dos princípios àquele do efeito":

Por exemplo, na operação kitsch, um vidro se torna "novo e original", quando suas dimensões são tão ampliadas que escapam da escala em relação a sua função, mas elas ainda permitem, entretanto, que 
esta função seja executada; ao contrário do que acontece no processo de "pop" que se baseia na dimensão do inutilizável. Ou, ainda, no kitsch, o desvio é conseguido através do uso de material impróprio, pela camuflagem da função, ou pelo contraste entre a forma incongruente, que é sempre apresentada como a forma de alguma coisa reconhecível, e da própria função ela mesma: um barco que é mais leve que um isqueiro, um isqueiro que parece um batom, um batom que lembra a Torre de Piza'13 (Gregoretti, 1978, p. 265).

Ora, aqui os autores ainda se situam no contexto da alienação e da má-fé do homem kitsch. Entretanto, eles nos ensinam que o sistema kitsch utiliza a lógica do empilhamento, da heterogeneidade, da sedimentação, da transposição e do deslocamento. Esta caracterização lógica é bastante instrutiva e não hesitaremos em retomá-la na construção da "forma" kitsch. Mostraremos a seguir como esta "forma" é dinamizada pelos procedimentos da bricolagem e da alegoria.

\section{Representações populares: da bricola-}

\section{gem à alegoria}

Pode-se pensar que as representações estéticas consideradas naïfs (aquelas das crianças, arte popular, mas também de uma vanguarda artística que lhe empresta o nome) parecem depreender-se da lógica da bricolagem explicada por Lévi-Strauss (1990). Para o autor, extrair o objeto de seu contexto espaço-temporal para colocá-lo em outra ordem constitui um procedimento bastante próximo da forma lógica subjacente às manifestações consideradas naïfs.

Como o bricoleur, a criança, o artista primitivo ou o artista popular tentam extrair novos significados dos

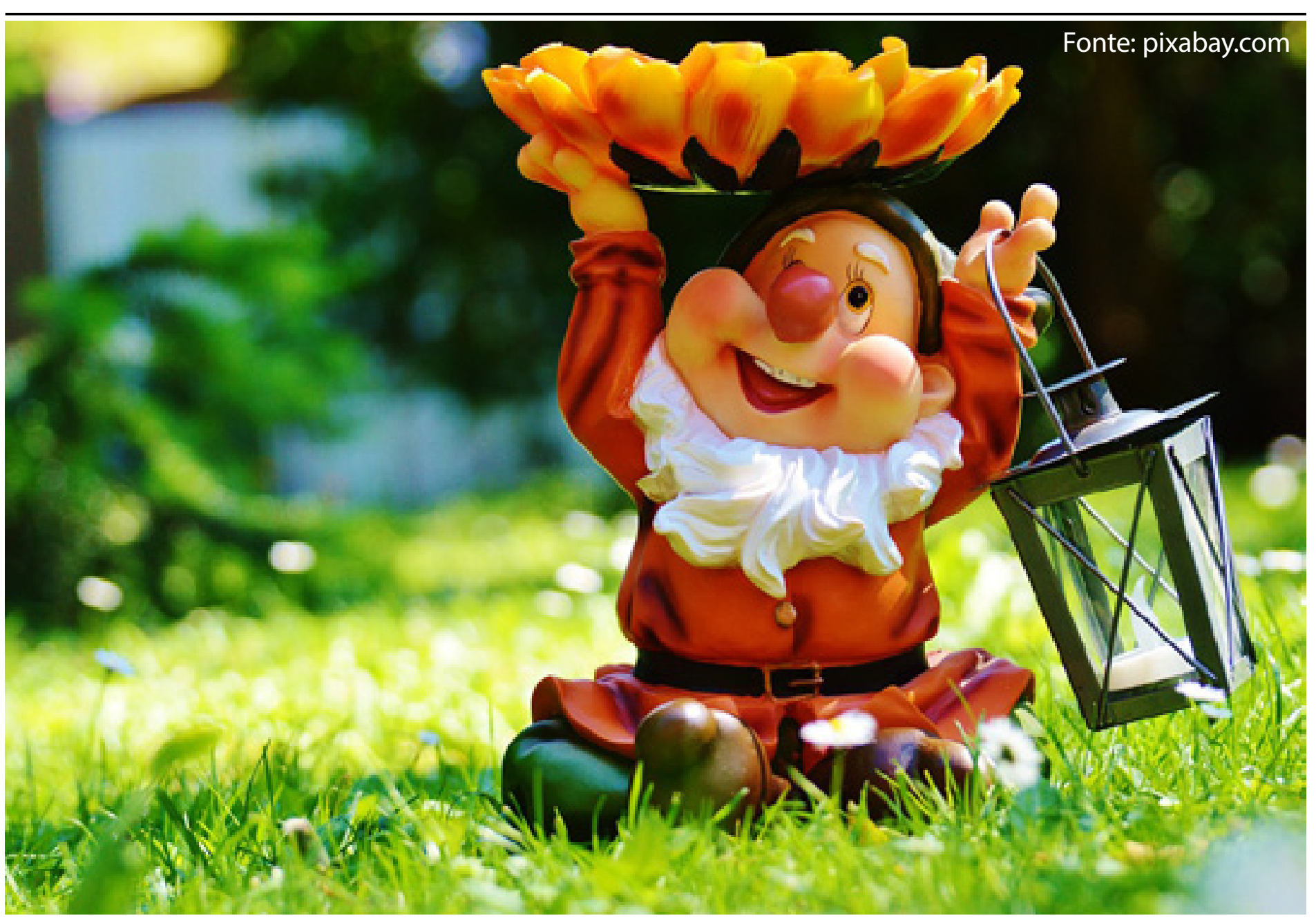


objetos que eles reuniram em uma coleção, segundo o princípio de que "isso pode sempre servir"14 (Lévi-Strauss, 1990, p. 31). Como o bricoleur, na situação de uma determinada tarefa, eles interrogam cada um destes objetos díspares esperando que deste emerjam novas significações, além daquelas que este já possuía antes. Será então, a partir deste novo repertório de possibilidades, que a melhor solução será escolhida.

Adentramos aqui em uma concepção de mundo algo mítica, uma vez que a cultura e história não são elementos fundadores. De fato, sob o prisma deste pensamento, a cultura e a história (enquanto ordem progressiva) não entram em consideração. A cultura é desmantelada em fragmentos residuais e o mundo só toma sentido dentro dessa coleção finita de pedaços de objetos que o constitui. À maneira do caleidoscópio que realiza arranjos estruturais com os fragmentos, o pensamento não domesticado encontra então seus significados a cada mudança de peças no conjunto finito de resíduos de cultura.

Se seguirmos o esquema do bricoleur proposto por C. Lévi-Strauss, as representações plásticas populares também permanecem aquém da cultura; isto equivale a dizer que o mundo encontra-se sempre finito. Veremos também que uma determinada espessura da humanidade (que inclui também seu aspecto de natureza) passa a fazer parte desta realidade. Existe sempre um fator inseparável natureza-cultura que destrói os projetos essencialmente culturais.

Um procedimento vizinho àquele da bricolagem e que supomos se aproximar da experiência popular é o procedimento alegórico. A crítica às representações de mundo estáveis e fixas é que são, como observa Michel Maffesoli, espetáculos frequentes nas massas. Haveria neles um relativismo cínico, uma "imoralidade em rela- ção aos valores oficiais, uniformes e unidimensionais"15 (1985, p. 51). Perguntamos: este processo não equivaleria àquele da "desconstrução' que a alegoria faz das coisas? Lembramos que a alegoria expressa uma ideia abstrata por meio de imagens que se seguem. E mesmo a paró dia, pode, em certas circunstâncias, ocorrer no processo alegórico. Nesse caso, um número de elementos contraditórios chega a ser a expressão de uma ideia. Isto é, a paródia desvia o sentido original das coisas e as relativiza, contribuindo assim para esta expressão alegórica.

Neste contexto também é possível estabelecer comparações com a vida social. Quando Michel Maffesoli (1990) observa que as massas têm o hábito de se investir de aparências e de respeitabilidade enquanto praticam o "sistema D", isto é, a nosso ver, um proces so alegórico. Pela alegoria as visões monovalentes das coisas são colocadas em perspectiva e, em alguns casos, desmanteladas.

Além disso, assim como o procedimento da brico lagem, a alegoria tem um parentesco com o sistema mítico. A "alegoria (..) inclui o mito, cuja essência encontra sua expressão mais perfeita na progressão épica"16 lembra Benjamin (1986, p. 177). Nesta progressão épica os objetos se encontram fragmentados e descontextu alizados de seu lugar em direção a outro plano, plano este que Benjamin nomeia como transcendente. E do mesmo modo que Michel Maffesoli (1979) observa que o gosto do espalhafatoso e da generosidade do detalhe presente na ornamentação popular não simboliza o absoluto, mas um eterno presente, pode-se supor uma proximidade da alegoria com o mito. Ora, a multiplicidade de detalhes proveniente de várias origens e empiIhamento de estilos utilizados muitas vezes na estética popular não se relaciona, certamente, com o conceito de "bom gosto" de estetas e intelectuais conservadores.
No entanto, é com este sistema que o "parecer" na massa popular atinge a sua dimensão do sublime.

Em sua obra Origem do Drama Barroco Alemão (1986), Walter Benjamin observa que o barroco expressa uma crítica da cultura, crítica que está em relação estreita com o gosto popular. Para ele, o mundo do barroco se dissolve em um acúmulo de ruínas, já que destrói a conexão entre as coisas. E observa, em uma linguagem poética, que "cada peça do mosaico e cada fragmento do conjunto se eleva em direção a uma nova vida no momento em que ele toma significado na interpretação alegórica"17 (Benjamin, 1986, p. 187). Isto equivale a dizer que o elemento particular morre, mas eleva-se ao plano das ideias e torna-se uma totalidade. O objeto é arrancado de suas conexões espaço-temporais, mas torna-se objeto de conhecimento: um saber que torna evidente a falácia de contexto. Benjamin escreve:

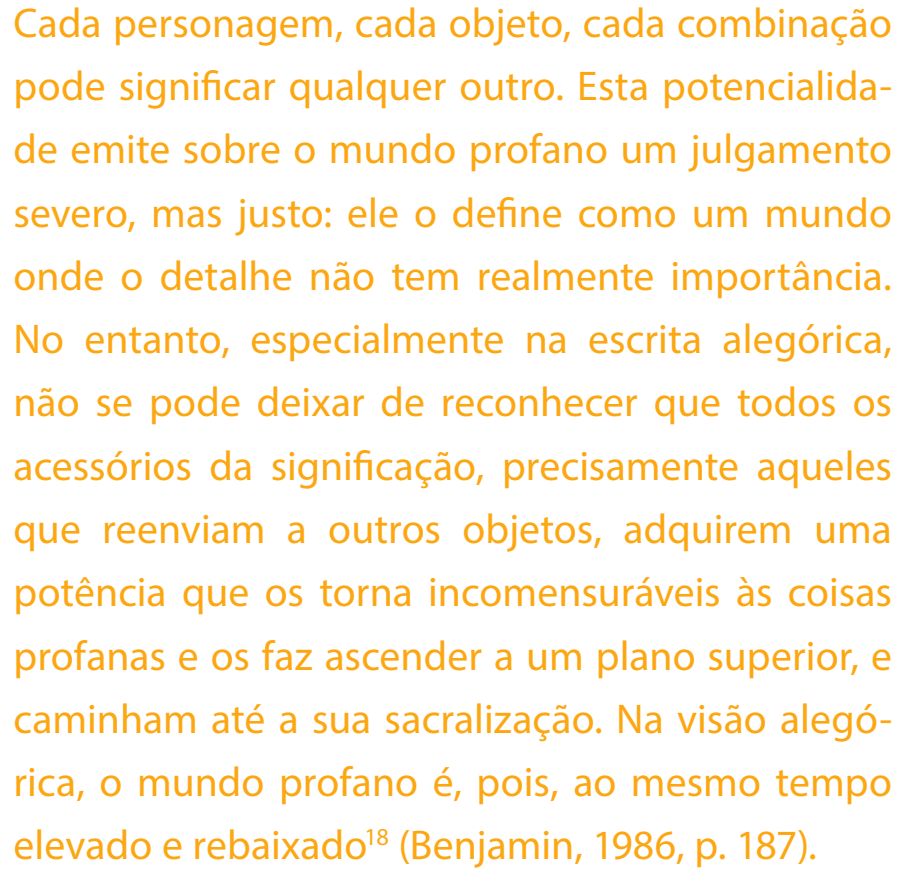


É dentro deste contexto que pressupomos que certas práticas frequentes nas manifestações estéticas populares como aquelas em que se colocam as coisas fora de seu contexto e com ênfase nos detalhes podem trazer ressonâncias deste modo operacional da alegoria. Um olhar sobre o conjunto de mercadorias expostas por comerciantes no centro da cidade de São Paulo nos revela rapidamente uma mistura insólita: de ervas e especiarias à eletrônica, passando pelos bonecos de pelúcia, as máscaras, as bijuterias, roupas, material escolar, etc. Os mercados de pulgas de uma grande cidade como Paris, por exemplo, oferecem igualmente coisas empilhadas ao acaso: crucifixo, talco, fotos antigas, relógios, ursos de pelúcia, coleções de livros, cristais, vasos de porcelana, talheres, panelas, etc. A organização de objetos aí é comparável: ausência de ordem, superposição e heterogeneidade dos objetos.

Essa lógica das feiras ambulantes existe no Brasil desde o século XIX (principalmente no Nordeste). No mercado de barracas se superpõem artesanato, ervas, fotografias a cores, almanaques ilustrados e cantores de louvor ao Nordeste, etc. Na França estes antecedentes datam de longa data. J. Cuisenier descreve o mascate como vendedor de flores, facas, lâminas de barbear, panelas, colheres, lâmpadas, bolsas, espelhos, sabonetes e todo tipo de pequenos objetos. A esses objetos díspares se adicionava a distribuição de imagens e livros (1987, pp. 292-298).

Esta composição de objetos heterogênea de materiais que também se reflete no discurso oral dos mascates é típica, de acordo com M. Bakhtin (1970), dos mercados e cultos populares dos séculos XV e XVI. O autor explica que esta prática reunia uma enorme variedade de objetos e que empregava formulações orais compostas de intermináveis séries de nomes e títulos ou acú- mulo de verbos e adjetivos. Essas enumerações eram, segundo ele, sonoras, solenes e longas. Tornavam-se muitas vezes abusivas e irreverentes (Bakhtin, 1970, p. 369).

Tal enumeração de objetos é efetuada em um misto de louvor e abuso, que, segundo o autor, rebaixava o mundo mas permitia uma nova transcendência das coisas. Por essa enunciação o homem se aproximava do todo, ele

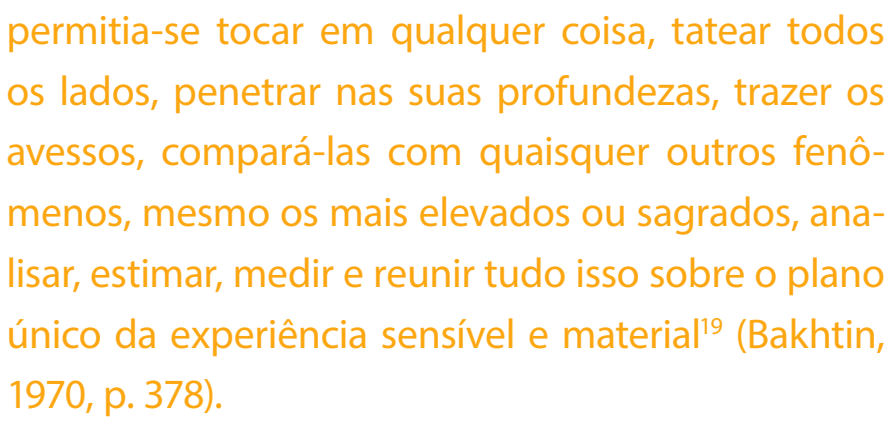

É assim que, segundo Bakhtin, o mundo se reveste de um aspecto material "mais próximo do homem e de seu coração, mais compreensível, acessível, fácil e onde as coisas tomam sentidos diferentes, familiares e mais leves, desprovidos de medo"20 (Bakhtin, 1970, p. 377).

Enfim, como observamos, a lógica de composição de mercados ambulantes contemporâneos, também conhecidos como "mercados de pulgas", se aproxima dos mecanismos de alegoria citados por W. Benjamin. Ou, como na alegoria barroca, há aqui um processo de desconstrução do mundo. Trata-se de uma multiplicidade de imagens diversas que, extraídas do seu contexto, fragmentadas e em mosaico, expressam o mundo em ruínas. O particular morre, mas, como reflete Benjamin (1986, p. 187), "cada fragmento do todo sobe para uma nova vida, quando ele assume o significado na interpretação alegórica"21.
Se quisermos arriscar uma representação espacial, poderemos dizer que a aglutinação de coisas heteróclitas provenientes de origens diversas, a multiplicidade de pequenos objetos nos conduzem a um universo topológico onde os objetos perambulam soltos. Ao mesmo tempo descobrimos aí um sentido transcendente. A imagem que nos oferece W. Benjamin é esclarecedora neste aspecto:

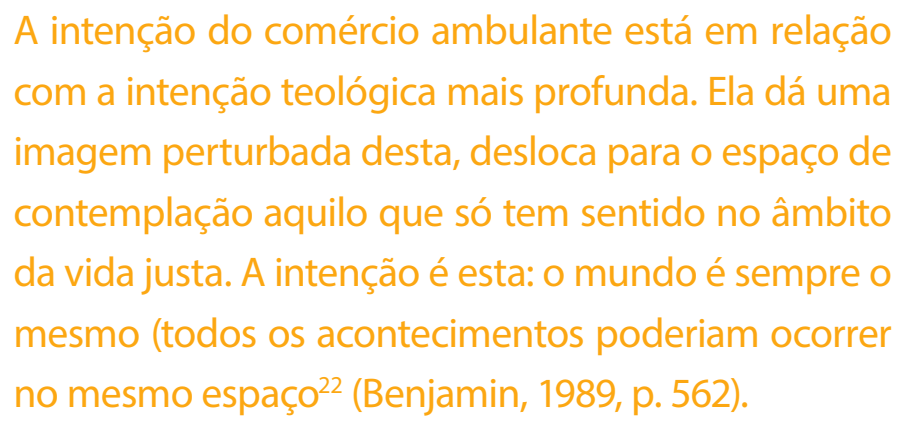

Voltamos à lógica da alegoria e podemos dizer com Benjamin que "as alegorias estão para o domínio do pensamento, aquilo que as ruínas determinam para o domínio das coisas. Daí o culto barroco da ruína"23 (1986, p.191).

\section{A arte culta e as práticas}

\section{artístico-tecnológicas}

Trataremos agora dos prolongamentos desta lógica da bricolagem e da alegoria no eixo da arte consagrada e das práticas artístico-tecnológicas. Assim como nos eixos anteriores, este eixo também se movimenta dentro da dinâmica da fragmentação e da totalidade.

De fato, por um lado a arte e as práticas artístico-tecnológicas parecem compartilhar o mesmo gosto pela decomposição do objeto e da sobreposição do espaço e tempo. Por outro lado e em um processo simultâneo, uma procura de universalidade também é efetuada. 
Ora, no que diz respeito à história das correntes estéticas, sabe-se que na arte consagrada todo o processo de fragmentação instaura-se a partir da decomposição do espaço tridimensional e da concepção de objeto clássica. O impressionismo já havia começado a desconstrução da arte figurativa. Ele havia quebrado o espaço e a luz em pontos. Os neoimpressionistas, como Gauguin e Seurat, empurraram em seguida, ao extremo, os princípios do impressionismo, com a introdução de divisionismo e do pontilhismo. Estes procedimentos consistiam em dividir e reduzir a cor pura ao menor elemento colorido e espacial.

Com Cézanne se impõe a decomposição fragmentária e reconstituição não mais da cor, mas do espaço. Ele procurava decodificar o espaço, colocá-lo de maneira plana a partir de uma combinação de fragmentos. Com o cubismo, espaço, tempo e objetos são completamente desmontados. O tempo de uma tela cubista, neste sentido, é um tempo quebrado. O presente é constituído por várias etapas. Seu espaço é uma multiplicidade de dimensões justapostas. O objeto é desmembrado em pequenos pedaços. Elementos díspares provenientes do «mundo real» podem participar desta decomposição: tecidos, fragmentos, jornais etc.

Pode-se dizer, de alguma maneira, que o cubismo promoveu o retorno da noção de espaço descontínuo, o esfacelamento do objeto e a deambulação dos fragmentos da arte popular. De fato, tudo isso se torna possível a partir da rejeição pelos cubistas das ilusões de espaço tridimensional do Renascimento e da perspectiva ortogonal fechada. Na nova perspectiva plana assim criada, os objetos deambulam pelos planos entrelaçados e intercambiáveis.

Sabe-se que as novas práticas tecnológicas que surgiram desde o final do século XIX, como o cinema e a televisão, foram beneficiadas pelas lições do cubismo. Elas também envolveram a fragmentação e sobreposição. É assim que a questão da montagem - no cinema e na televisão assim como nas imagens sintéticas - trazem novamente o universo topológico da arte popular e primitiva.

Nas práticas artísticas tecnológicas, a deambulação dos objetos, aquelas do tempo e do espaço convergem para a transcendência. Aqui apontamos a hipótese de que o menor elemento da imagem do computador o pixel, seria a expressão mais pura e mais atual dessa transcendência. O pixel seria o equivalente visual desse gosto do objeto e da transcendência que toma forma nos nossos dias.

É dentro dessa rede de conexões que o kitsch se encaixa como resultado. O que é chamado de kitsch hoje retoma não somente o passado, mas mistura todos os tempos: o passado, o presente e o futuro. Não podemos mais considerar como mero kitsch revival, mas como uma justaposição louca que quebra a possibilidade de um sentido único. Na nova estética, kitsch de tempo e de espaço coexistem. Tudo reenvia a tudo

Todas as referências arcaicas, modernas e pós-modernas se tornaram alegorias colocadas no mesmo nível. Opostos coabitam e se sobrepõem. Esta é a metamorfose pura, a intercambialidade. Apesar de sua simplicidade, o kitsch consegue fazer várias combinações dentro da multiplicidade de dados mundanos. E na confusão de estilos, na fragmentação de peças e estilos se confundindo, procura um alcance maior. Em outras palavras, o aspecto multifacetado do objeto em si e a multiplicidade de modos de ser percebido, dá-lhe, paradoxalmente, um significado transcendente.

\section{Considerações finais}

É assim que, a partir de um estudo compreensivo (e não explicativo), propomos o conceito da "forma" kitsch. Acreditamos que a "forma" kitsch seria o resultado das influências da experiência popular e sua produção estética (incluindo a estética dos povos primitivos e das crianças que não pudemos desenvolver aqui) na arte culta e nas práticas artísticas e tecnológicas. Seria profícuo em um novo trabalho articular a existência de semelhanças entre essa configuração de kitsch atravessada por formas que circulam nestas esferas e algumas das configurações de sociabilidade contemporâneas. Ora, à maneira do deslocamento e da descontextualização da configuração kitsch, a massa social também se move. Ele já não pode ser considerado uma presença homogênea, estática e contínua, um "uno", pois esta não cessa de se unir e se dissolver, de se hibridar com ela mesma para engendrar novas composições. Do mesmo modo, à maneira da configuração estética do kitsch ocorre um vaguear, um perambular da massa social em um movimento plástico, elástico, sujeito a diferentes configurações. Maffesoli escreve:

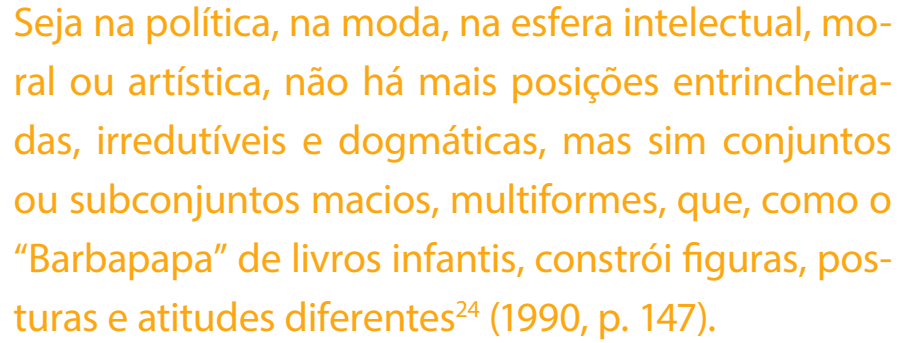

E é dentro deste contexto, em que os diversos estilos de vida, as diferentes "tribos" envolvem multiplicidades, que podemos perceber a derrota da singularidade 
irredutível das formas estáveis da modernidade. E também é dentro deste novo tempo que esta configuração proveniente do kitsch, tal como a descrevemos, torna-se clara o suficiente para ser apreendida.

\section{Referências}

BAKHTIN, Mikhail. L'oeuvre de François Rabelais. Paris: Ed. Gallimard, 1970

BENJAMIN, Walter. Origine du drame baroque allemande. Paris: Ed. Grasset, 1986.

BENJAMIN, Walter. Capitale du XIX siècle. Paris: Ed. Les éditions du cerf, 1989.

$\mathrm{BROCH}$, Herman. Quelques remarques sur le problème du kitsch. In: Le kitsch, un catalogue raisonné du mauvais goût. Paris: Ed. Complexe, 1978.

CARDOSO, Rafael. Uma introdução à história do design. São Paulo: Blucher, 2008.

CUISENIER, J. L'art populaire em France. Paris: Les Edtions Arthaud, 1987.

DORFLES, G. (org.). Le kitsch, un catalogue raisoinné du mauvais goût. Paris: Ed. Complexe, 1978.

DORFLES, G. (org.). "Les transpositions", in DORFLES, G. (org.) Le kitsch, un catalogue raisonné du mauvais goût. Paris, Ed. Complexe, 1978.

CUISENIER, Jean. L'art populaire en France. Paris: Les Editions Arthaud, 1987, pp. 292-298.
DUVIGNAUD, Jean. La genèse des passions dans la vie sociale. Paris: PUF, 1990.

DUVIGNAUD, Jean. Le marché des choses inutiles. In: DORFLES, G. (org.) Le kitsch, un catalogue raisonné du mauvais goût. Paris: Ed. Complexe, 1978.

ECO, Umberto. Apocalípticos e integrados. São Paulo: Perspectiva, 1979.

GREGORETTI, Victor. Kitsch et architecture. In: DORFLES, G. (org.) Le kitsch, un catalogue raisonné du mauvais goût. Paris: Ed. Complexe, 1978.

LÉVY- STRAUSS, Claude. La pensée sauvage. Paris: Ed. Plon, Coll. "Presses Pocket", 1990.

MAFFESOLI, Michel. La conquête du présent. Paris: Ed. PUF, 1979.

MAFFESOLI, Michel. La Connaissance Ordinaire. Paris: Ed. Librarie des Meridiens, 1985.

MAFFESOLI, Michel. Au creux des apparences. Paris: Ed. Plon, 1990.

MOLES, A. Psychologie du kitsch. Paris: Ed. Médiations, 1971

SIMMEL, Georges, Sociologie et epistémologie. Paris: Ed. PUF, 1981.

WAJNMAN, Solange. Forma kitsch e teoria pós-moderna. In: Atrator Estranho. São Paulo: Edições NTC/ECA-USP 1996, n.27.
WEBER, Max. Metodologia das ciências sociais. São Paulo/Campinas: Cortez/Editora da Unicamp, 1993.

Notas

1 Doutora em Sciences Sociales pela Universite Rene Descartes, Sorbonne. Pós-doutora pela Escola Superior de Teatro e Cinema de Lisboa -ESTC e pelo departamento de Estudos Literários da Universidade Federal Fuminense. Professora titular do Programa de Pós-graduação em Comunicação na Universidade Paulista (UNIP). (Programa de Mestrado em Comunicação, Campus Indianópolis. Rua Dr. Bacelar 1212, Vila Clementino, São Paulo/SP, Brasil, CEP: 04026-002).E-mail: wajnman@aclnet.com.br.

2 Remetemos o leitor para o livro de Georges Simmel, Sociologie et epistémologie, Paris, Ed. PUF, 1981, e para o livro de Michel Maffesoli, La connaissance ordinaire, Paris, Ed. Librarie des Meridiens/Klincksieck, 1988.

3 "La 'forme est formante et non point formelle" (tradução da autora).

4 “Ils'agit là, d'habitude, d'une incompréhenson qui ne s'applique qu'à l'art moderne ou aux oeuvres anciennes 'difficilles' (c'est à dire aux plus sérieuses); et elle affecte les individus qui croient qu'il ne faut tirer de l'art que des impressions agréables, plaisantes, douces, ou qui pensent même que l'art doit servir de 'condiment', de' musique de fond', de décoration, de symbole de position sociale, et non pas de composant grave de l'existence, d'exercice pénible, d'activité angagée et critique" (tradução da autora). 
5 "Em quel type d'oeuvre d'art, ou plutôt, d'artifice, Le kitsch tend-il à transformer la vie humaine? La réponse est simple: em oeuvre d'art névrotique, en oeuvre qui impose à la réalité une convention complètement irréelle em l'emprisionnant dans um schéma faux" (tradução da autora).

6 - sécurité vis-à-vis des áléas du monde extérieur qui se propose comme une valeur idéale

- affirmation de soi-même, absence de mise en question d'un mode de vie ou d'un système économique basés sur l'accumulation créatrice et sur la conservation, qu'il s'agisse de capital, de marchandises, de grands magasins ou d'objets

- système possessif comme valeur essentielle ou l'être est ce qu'il paraît et paraît par ces possessions; grandeur de l'appartement, hauteur des plafonds, ou argenterie.

- gemütlichkeit liée à l'âme et au coeur, intimité agréable et affectueuse, vertu de se sentir à l'aise - rituel d'un mode de vie (...)

7 Para $\mathrm{H}$. Broch, existiria um laço indissolúvel entre o romantismo e o homem kitsch. A exemplo da literatura romântica, por exemplo, o homem kitsch quer introduzir no reino da eternidade e da imortalidade, os aspectos mais terrestres da existência, o profano por excelência (...)", op.cit., pp. 71-72).

8 "I'utilisation consciente et intentionnelle des éléments du kitsch par certains artistes contemporains (Duchamp, Picasso, De Chirico, etc) ainsi que I'utilisation par um public d'élite, culturellement sophistiqué, d'éléments appartenant nettement au kitsch (meubles, objets de décoration, tableaux, statues etc) mais rachetés par une certaine attitude de la part du consommateur, (...) et qui constitue en un certain sens le contre-pied du kitsch" (tradução da autora).

9 "l'essence du Camp est son amour pour ce qui n'est pas naturel, pour l'artifice, pour l'excès" (tradução da autora)

10"Le Camp est donc une attitude particulière, sophistiquée et une tantinet snobinarde, par laquelle s'opère une sorte de rachat, de récupération d'un matériel autrement destiné, souvent sinon toujours, à la poubelle. Dans l'autre cas, Le Camp permet de réévaluer ce qui, en soi, n'aurait eu que peu de valeur" (tradução da autora).

111) Critère d'entassement sans dommage: Un ensemble kitsch est constitué d'objets diversifiés et entassés dans um espace volumique à superficie restreinte. (...)

2) Critère d'hétérogéneité: Les objets assemblés n'ont pas de rapport direct les uns avec les autres (...) 3) Critère d'antifonctionnalité: Celui-ci correspond à la distinction entre la série fonctionnelle, celle par exemple des instruments de chirurgien posés l'un à côté de l'autre sur la tablette de service prés de la table d'opération, celle de la batterie de cuisine d'un restaurant, ou la série d'instruments de I'Institut de beauté, et Le groupement spontané à caractere sédimentaire de la collection de casseroles de toutes les tailles et de toutes formes, ou celle de fers à repasser, de la cuisine ou du salon bourgeois. La fonctionnalité impose dês séries precises d'objets répondant à dês critères utilitaires.
4) Critère de sédimentation: Le kitsch est rarement Le produit d'une intention délibérée comme ce pourrait être Le ces cãs pour um décorateur. Il est, au contraire, um lent développement, une accumulation triomphante, trophées de voyages et témoignages d'exotisme, trophées d'ascension sociale, ou sócioéconomique, gages d'une séduction par Le marche et d'une pensée artistique atomisée qui voit clairement l'objet, mais mal l'ensamble, et NE connaît que la coehérence du sédiment ou du tas, de la séquence dês tentations plutôt que du projet d'ensamble" (tradução da autora).

12 "[...] Le rapprochement entre um tableau de Cézanne et le bleu d'une chemise de sport; l'association entre une branche de corail et le parfum de même nom, dans laquelle les connotations exotiques du produit marin accentuant l'ambiguité formelle; la comparaison entre une voiture rapide ( donc de haut prestige) et la 'vélocité'd'une page de Beethoven, à propôs d'une installation stéréophonique montable au tableau de bord d'une automobile; enfin l'intégration d'un bouquet de fleurs dans une cuvette de W.C à ventilation automatique" (tradução da autora).

13“Par exemple, dans l'opération kitsch, um verre devient 'nouveau et original' lorsque ses dimensions sont agrandies jusqu'au gigantisme et hors d'échelle par rapport à sa fonction, mais qu'elles permettent néanmoins à cette fonction de s'accomplir; contrairement à ce qui se produit dans le processus 'pop'qui, lui, se fonde sur la dimension de l'inutilisable. Ou bien, dans Le kitsch, la diversion est obtenue par I'usage d'un matériau impropre, par le camouflage 
de la fonction, ou par l'opposition incongrue entre la forme, qui se présente toujours comme la forme de quelque chose d'autre de bien reconnaissable, et la fonction elle-même: um voilier qui est em réálité um briquet, un briquet qui ressemble à un bâton de rouge à lèvres, un bâton de rouge à lèvres qui ressemble à tour de Pise" (tradução da autora).

14 "ça peut toujours servir" (tradução da autora).

15 "immoralisme vis à vis des valeurs offielles, uniformes et unidimensionnelles" (tradução da autora).

16 “'́allégorie (...) comprend le mythe, don't l'essence trouve son expression la plus parfaite dans la progression épique" (tradução da autora).

17 "chaque éclat de la mosaïque et chaque fragment de I'ensamble s'élève À une nouvelle vie au moment ou Il prend de la signification dans la lecture allégorique" (tradução da autora).

18 "Chaque personnage, chaque objet, chaque combinaison peut signifier n'importe quelle autre. Cette potentialité émet sur Le mode profane um jugement sévère, mais juste: elle Le définit comme um monde ou Le détail n'a pas vraiment d'importance. Pourtant et surtout si l'on est au fait de l'écriture allégorique, on ne manquera pas de reconnaître que tous les acessoires de la signification, précisément par ce qu'ils renvoient à d'autres objets, acquièrent une puissance qui les rend incommensurables aux choses profanes et les fait accéder à um plan supérieur, et qui parfois va même jusqu'à les sacraliser. Dans la vision allégorique, le monde profane est donc au même temps elévé et abaissé" (tradução da autora).
19 "permettait de toucher n'importe quelle chose, de la tâter de toutes parts, de pénétrer dans ses profondeurs, de la retourner à l'envers, de la confronter avec n'importe quel autre phénomène, si elévé et sacré fût-il, d'analyser, estimer, mesurer et ajuster tout cela sur le plan unique de l'expérience sensible et materielle" (tradução da autora).

20 "plus proche de l'homme et de son coeur,plus compréhensible, accessible, facile, et tout ce qu'on en dit prenne à son tour des accents différents, familiers et gais, denués de peur" (tradução da autora).

21 "chaque éclat de fragment de l'ensamble s'élève à une nouvelle vie au moment ou II prend de la signification dans la lecture allégorique" (tradução da autora).

22"L'intention du colportage est en rapport avec l'intention théologique la plus profonde. Elle donne une image trouble de celle-ci, déplace dans l'espace de la contemplation ce qui n'as sens que dans celui de la vie juste. Cette intention, c'est celle-ci: le monde est toujours le même (tous les événements auraient pu avoir lieu dans le même espace)" (tradução da autora).

23 "les allégories sont au domaine de la pensée, ceque les ruines sont le domaine des choses. D'où le culte baroque de la ruine" (tradução da autora).

24 "Que ce soit dans la politique, la mode intellectuelle, la sphère morale ou artistique, II n'y a plus de positions tranchées, irréductibles et dogmatiques mais plutôt des ensambles ou sous-ensambles mous, pro- téiformes, qui, à l'image dês 'Barbapapa' des livres d'enfants, prennent des figures, des postures et des attitudes diverses" (tradução da autora). 